\title{
Mudança fictiva em corpus de fala espontânea do PB
}

\author{
Luiz Fernando Matos Rocha ${ }^{a}$ \\ Luciana Andrade Paula \\ Márcia do Prado Andrade
}

\begin{abstract}
Resumo
Este trabalho investiga construções linguísticas de mudança fictiva em corpus de fala espontânea do Português Brasileiro (PB). Instanciam-se em exemplos como O quarto ficou muito maior depois que retiraram os móveis, em que uma mudança expressa pelo predicado ocorre apenas em função da percepção/concepção do conceptualizador. Em outros termos, o quarto não tem suas dimensões concretamente ampliadas, porém o caráter resultativo dessa mudança se dá apenas no plano subjetivo. Alguns autores em Linguística Cognitiva (LC) vêm tratando desse fenômeno, como Sweetser $(1996,1997)$ e Matsumoto (1996), os quais mostram que a visão de um dado objeto passa a assumir outra dimensão, forma ou estado quando ocorre uma mudança na percepção do conceptualizador. Tais aspectos teóricos lançam as bases da verificação de viabilidade empírica da categoria mudança fictiva em dados reais de fala do PB. Para tanto, a metodologia se alinha à busca de ocorrências de verbos de mudança de estado (e.g. "ficar", "virar", "tornar") na parte informal do corpus C-ORAL-BRASIL (RASO $\mathcal{E}$ MELLO, 2012), associada à oitiva dos arquivos em áudio. Com isso, foram elencados padrões de extensão espacial, temporal e corporal, em que a mudança é apenas de caráter subjetivo ou fictivo. Os resultados ainda apontam para o fato de que a construção se relaciona a uma quebra da expectativa default (ou seja, quartos não têm suas dimensões alteradas por conta da retirada de móveis), resultando em algo que só existe conceptualmente (ou seja, ocorre uma construção resultativa, em que o quarto se torna subjetivamente maior).
\end{abstract}

Palavras-chave: Cognição; Fictividade; Mudança fictiva; Corpus; Fala espontânea.

\footnotetext{
a Professor e pesquisador da Faculdade de Letras da UFJF, luiz.rocha@ufjf.edu.br

b Graduanda da Faculdade de Letras da UFJF, luciana.andrade.paula@gmail.com

c Graduanda da Faculdade de Letras da UFJF, marcia.ufjf@gmail.com
} 


\section{Introdução}

Em Linguística Cognitiva (LC), a expressão subjective change ${ }^{1}$ (mudança subjetiva) ou fictive change (mudança fictiva) remete uma categoria de análise para fins de estudos semânticos, a qual perfila não necessariamente uma mudança de caráter emocional na subjetividade do conceptualizador ${ }^{2}$, mas uma sensação de mudança percebida/concebida e linguisticamente manifestada pelo conceptualizador. De acordo com os trabalhos seminais acerca desse tema (TALMY, 1983; LANGACKER, 1987, 1988), predicados que, normalmente, descrevem mudança objetiva podem também evidenciar pontos de vista de escaneamento subjetivo (fictivo) sobre a extensão temporal ou espacial. Trata-se de uma operação cognitiva na qual o conceptualizador constrói uma imagem mental acerca de determinada cena, alinhado às suas próprias impressões sensoriais e em contraposição ao domínio concebido como realidade.

Essa alternância semântico-descritiva pode ser observada em Português Brasileiro (PB), por exemplo, nos predicados que apresentam o verbo "ficar" como predicador de mudança de estado ou de condição, significando "passar a ser ou estar,

1 A discussão terminológica é relevante à medida que a expressão "mudança subjetiva" pode reduzir o fenômeno, de modo equivocado, a um viés interpretacionista. Por isso, dá-se preferência ao termo "mudança fictiva", em português.

2 Para Langacker (2008), conceptualizador é o "visualizador" que concebe e percebe o significado das expressões linguísticas: falante e ouvinte.

3 "As entidades fictivas podem ser representadas a partir de um substantivo comum interpretado como substantivo coletivo. Prototipicamente, o plural semântico é estabelecido por um item morfossintaticamente marcado pelo singular" (ROCHA et al., 2013, p. 77). tornar-se". Tais predicados tanto podem descrever mudança objetiva, como em (1) A casa ficou muito espaçosa ao final da reforma, haja vista a ampliação física do imóvel; quanto podem descrever mudança subjetiva, como em (2) A casa fica muito espaçosa depois da instalação de espelhos. Independentemente da permuta do tempo verbal (de "ficou" para "fica"), o enunciado (2) apresenta a perspectivação conceptual de uma sequência subjetivamente escaneada, visto que a instalação de espelhos provoca uma impressão de ampliação de espaço, não verificável no plano concebido como real.

Para os predicados de mudança, Sweetser $(1996,1997)$ estabelece dois parâmetros de interpretação: o de leitura individual e o de leitura papel. No primeiro, a interpretação do enunciado o restringe à ideia de valor semântico preenchido. Em (1), o item "casa" evoca um referente específico, individualmente instanciado. De acordo com a leitura papel, "casa", em (2), apresenta-se como uma entidade fictiva ${ }^{3}$ (ROCHA et al., 2013), cuja interpretação é tomada como genérica. Isso contribui para 
o entendimento da mudança fictiva, já que a noção de papel compreende uma classe abstrata necessariamente desengajada de suas instâncias.

Outro elemento pode ser aludido quanto à genericidade do enunciado (2): o tempo verbal presente do indicativo ("fica") instaura um aspecto gramatical de habitualidade genérica, não necessariamente vinculado a um evento específico como ocorre em (1), mas a um abstraído de muitos eventos de rotina. Tratase de um predicado de instanciação fictiva, tido por Langacker (2008) como algo que emerge por generalização, representando o senso comum e invocando um modelo cultural que retrata o mundo como tendo uma estrutura essencial. Devido ao fato de os enunciados genéricos fazerem parte da representação do mundo, não do mundo em si, o evento e seus participantes são apenas virtuais, instâncias representativas de seus tipos.

Pistas linguísticas como essas, vinculadas à abstração, habitualidade e genericidade, induzem à postulação de que existe um conhecimento partilhado entre os conceptualizadores (acerca de situações, relações, experiências, crenças ou conceitos etc.), o qual fomenta expectativas culturais, sociais e psicológicas estabelecendo-se um conjunto de probabilidades acerca do mundo. Quando um elemento objetivamente improvável se apresenta, por força da probabilidade subjetiva, ocorre quebra de expectativa em relação aos padrões de idealização frequentes e legitimados, criando um ambiente propício para expressões de mudança subjetiva (MATSUMOTO, 1996).

A expressão de mudança fictiva, em japonês, ilustra o gerenciamento conceptual de probabilidades, que envolve a quebra de expectativas default. Segundo Matsumoto (1996), o japonês perfila morfossintaticamente a mudança fictiva pelo acréscimo da partícula te-iru às construções típicas de mudança objetiva, dando-lhes um caráter resultativo, como se verifica no enunciado abaixo:

(3) Sono heya wa maruku natte iru.

O quarto TOP redondo tornar-se RES

(Lit. O quarto está no estado de ter se tornado redondo) 'O quarto ficou redondo.'

A partícula te-iru impõe um perfil à construção que evidencia uma mudança de caráter não usual, contrariando expectativas de modelos culturais preestabelecidos. Espera- 
se que um quarto seja retangular ou quadrado e não necessariamente redondo, como no exemplo (3). Entretanto, se a referida partícula for usada em construções de mudança objetiva, condizentes com a expectativa, ela as torna gramaticalmente inadequadas, como se observa em (4):

(4) \# Sono heya wa shikakuku natte iru.

O quarto TOP retangular tornar-se RES

(Lit. O quarto está no estado de ter se tornado retangular)

'O quarto ficou retangular.'

O uso de (4) só pode ser admitido, em japonês, caso a quebra de expectativa seja mantida e se antes o quarto apresentava outra forma diferente da retangular. Ou seja, dá-se relevo à historicidade dos elementos em mudança. $\mathrm{O}$ entendimento acerca de possibilidades de uso da construção de mudança fictiva em dados do japonês sugere que o fenômeno também tenha suas manifestações linguísticas específicas em outros idiomas. Um aspecto a ser destacado é o fato de que a mudança fictiva leva em consideração um objeto que passa por um processo abstrato e inusitado de mudança, que ocorre apenas na mente do conceptualizador. Assim, as expressões subjetivamente resultativas descrevem uma situação não usual como se fosse uma variação de um estado ideal ou usual da expectativa default, construída com base em sua historicidade.

Na concepção da LC, a mudança fictiva expressa nos predicados ocorre quando o conceptualizador tem uma impressão de mudança, mesmo podendo estar consciente de que essa transformação não existe no mundo real, ou seja, ela não ocorre de fato, mas é como se ocorresse. Cria-se um domínio linguístico verossímil para a conceptualização da mudança, estabelecendo-se uma espécie de conflito cognitivo do tipo "parece-mas-não-é", que é interacionalmente superável. O falante/ouvinte sabe que a mudança não é real, mas acata a realidade perceptual, tornando-a aceitável no plano sociointeracional.

Considerando a historicidade semântica do enunciado fictivo (5), O quarto está redondo, pode-se constatar que determinado ambiente é, de modo pressuposto, quadrado, porém ele pode se tornar perceptualmente redondo devido 
à disposição dos móveis de uma maneira que o deixe em um formato arredondado. É interessante notar que seria viável a edificação de um quarto redondo. Todavia, conforme nossos conhecimentos prévios e usuais, é esperado um padrão de quarto retangular ou quadrado, pois esses cômodos frequentemente assim se apresentam.

O verbo "está", nesse caso, impele à consideração de uma projeção de passado e futuro para o formato do quarto, a partir do centro dêitico do evento de fala. Em outros termos, o quarto está redondo no aqui-e-agora da enunciação, porém se pressupõe que, no passado, possuiu outro formato e, no futuro, poderá ainda adquirir outro. Assim, uma mudança fictiva recorre a uma referência estabelecida, a um elemento esperado para que se possa tratar o inesperado. O estado esperado encontra-se pressuposto em uma situação incomum e, consequentemente, tal situação incomum só é percebida a partir do contraste com estado ideal construído em nossas mentes.

\section{Aspectos metodológicos}

Como aponta Rocha (2011), o histórico metodológico dos estudos sobre manifestações linguísticas da fictividade tem início com trabalhos baseados na intuição dos linguistas, que desenvolvem construtos epistemológicos induzidos a partir de ilustrações imagísticas e linguísticas, inventadas ou artificiais. É o que ocorre também com os estudos seminais e específicos sobre mudança subjetiva em um primeiro momento (SWEETSER, 1996, 1997; MATSUMOTO, 1996), os quais não explicitam a origem dos dados analisados e como foram tratados metodologicamente.

Não há como negar que a fase intuitiva de tratamento do fenômeno abre espaço para novas investigações, sobretudo àquelas de caráter empírico e cujo propósito é verificar categorias analíticas em dados reais de fala. A fundamentação metodológica está de acordo com a gênese cognitivo-social de seus aspectos teóricos, à medida que:

Entender o significado como conceptualização e reconhecer a importância dos aspectos sociais da cognição e da linguagem implicam uma metodologia empírica de observação do uso dos dados, e o modo mais natural de os encontrar é em corpora textuais representativos (SILVA, 2006, p.32). 
É exatamente na esteira desse compromisso analítico que se situa este trabalho, cujo objetivo é investigar a viabilidade das construções de mudança fictiva em dados de fala espontânea do PB. Com isso, espera-se ofertar ao arcabouço teórico retornos empíricos acerca da dimensão do uso dessas construções, evidenciando como a gramática engajada da língua opera com o arranjo subjetivo desse construal específico.

A pesquisa relatada neste trabalho lançou mão do C-ORAL-BRASIL (RASO \& MELLO, 2012) ${ }^{4}$. Com base na diatopia do estado de Minas Gerais (basicamente a região metropolitana da capital Belo Horizonte), o corpus prevê pelo menos 200 textos e 300.000 palavras, divididos em uma metade formal (a ser implementada) e uma metade informal (utilizada nesta pesquisa). De acordo com informações do site do C-ORAL-BRASIL, a metade informal (coletada entre os anos 2007 e 2010) se divide em um domínio privado/familiar (80\%) e um domínio público (20\%). Cada domínio se divide em monólogos (1/3), diálogos (1/3) e conversações (1/3). Submetido à ferramenta TextSTAT, esse grupo de dados apresenta 13.243 types e 233.934 tokens.

O método utilizado para o rastreamento das ocorrências de construções de mudança fictiva no referido corpus se deu em três etapas: (i) em função do caráter semântico do fenômeno, procedeu-se ao estudo das transcrições e oitiva simultâneas de todo o corpus, tendo como base fundamentos teóricos acerca do objeto para a verificação empírica inicial de sua manifestação e considerando-se que a informação prosódica influe na interpretação dos dados; (ii) do corpus e dos exemplos usados pelos teóricos de referência, depreendeu-se uma lista de verbos de mudança, a saber: alargar, ampliar, apagar, aparecer, apertar, emagrecer, engordar, estreitar, ficar, mudar, rejuvenescer, sumir, surgir, tornar, transformar, virar; e (iii) realizou-se o mapeamento e a separação dos usos fictivos, de construções com esses verbos, dos usos factivos. Para efeito de análise qualitativa dos dados, selecionaram-se excertos que dimensionam o fenômeno em termos discursivos.

\section{Mudança fictiva em dados reais de fala}

4 http://www.c-oral-brasil.org/

Na busca de pistas linguísticas características da mudança fictiva em corpus do $\mathrm{PB}$, deparou-se frequentemente com 
ambientes discursivos de descrição e narração. As ocorrências de predicado de mudança fictiva estão preferencialmente inseridas em um retrato verbal da cena, o qual pressupõe uma relação comparativa entre a anterioridade factiva do objeto descrito e sua posteridade fictiva. Tais predicados são de caráter descritivo por expressarem uma imagem percebida pelo conceptualizador, bem como de caráter narrativo, já que se inserem em uma sucessão mínima de acontecimentos.

O mapa dos predicados de mudança fictiva desenhado a partir do C-ORAL-BRASIL se mostrou pouco expressivo quantitativamente, porém, no plano qualitativo, revelou-se diversificado e complexo. Como os predicados revelaram um padrão formal vinculado ao uso de verbos de mudança, tornou-se relevante desenvolver uma tipologia, quanto ao significado, para distinguir os diferentes grupos de predicados de mudança fictiva: extensão espacial, extensão temporal e extensão corporal.

Essa tipologia, em parte, deriva do argumento de que predicados que, em geral, descrevem movimento ou mudança podem frequentemente ser usados para descrever pontos de vista de escaneamento subjetivo sobre a extensão temporal ou espacial (TALMY, 1983; LANGACKER, 1987, 1988; MATSUMOTO, 1986). Além de o corpus conter ocorrências de extensão espacial e temporal, o que corrobora a postulação do referido argumento, há casos em que o ponto de vista de escaneamento subjetivo incide sobre a extensão corporal. Isso representa um avanço no plano descritivo do fenômeno, que se mostrou condizente com os dados empíricos:

\subsection{Extensão Espacial}

Aspectos da mudança fictiva de extensão espacial podem ser compreendidos no exemplo logo a seguir, extraído de Matsumoto (1996, p. 141):

(5) The fence gets higher as you go down the road.

'A cerca fica maior à medida que você desce a rua.'

Em (5), o conceptualizador, à proporção que se desloca no percurso, elabora mentalmente uma sequência de imagens localizadas em pontos dessa trajetória, que lhe causa a 
impressão de alteração da altura da cerca, numa escala menormaior. Dessa forma, estabelece-se uma relação de figura e fundo: embora seja possível a multiplicidade de focos por parte do conceptualizador dinâmico, no fenômeno da mudança fictiva linguisticamente expressa, a trajetória é subfocalizada, atuando como o fundo, e cada imagem construída da cerca adquire status de figura. Veja nas ilustrações que seguem:

Figura 1a - Ponto de vista do conceptualizador externo e estático

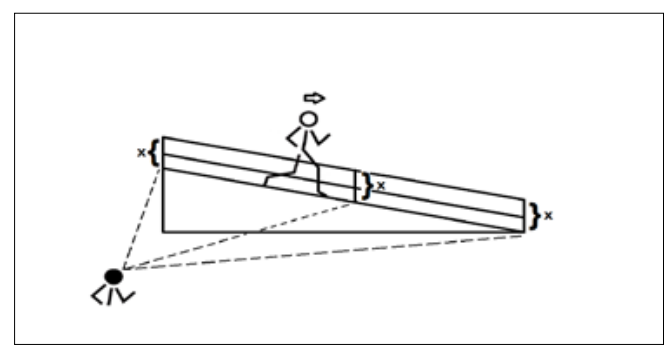

Figura $1 \mathrm{~b}$ - Ponto de vista do conceptualizador interno e dinâmico

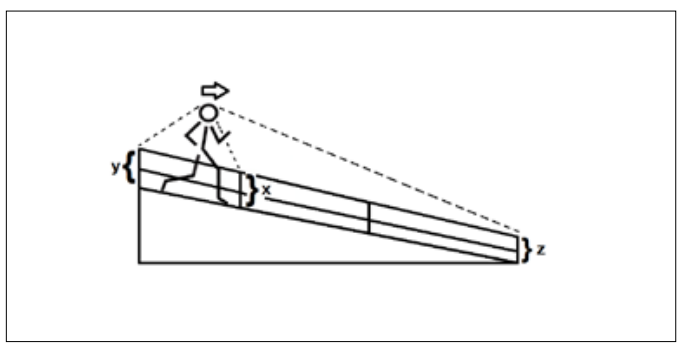

Observando-se a figura (1a), temos uma representação factiva da cena genuína, que parte do ponto de vista de um conceptualizador estático e externo. Assim, em (1a), a cerca permanece do mesmo tamanho, e o único elemento que se move é a pessoa observada. Na figura (1b), representa-se o processo de escaneamento mental realizado pelo conceptualizador que desce a ladeira. Portanto, para o observador externo de (1a), a cerca não altera seu tamanho, tendo sua medida constante, igual a $x$. Entretanto, para o conceptualizador dinâmico e interno (1b), a cerca tem seu tamanho perceptualmente alterado conforme sua distância em relação a ela, equivalendo em cada 
ponto da trajetória a $y, x$ e $z$; sendo ainda $y>x>z$. Dessa forma, o enunciado (5) é possível e corresponde à impressão não genuína do conceptualizador, já que seu andar não acresce, de fato, o tamanho da cerca, caracterizando, assim, o fenômeno da mudança fictiva.

Com o exemplo (6), adiante, retirado do corpus de fala C-ORAL BRASIL (RASO \& MELLO, 2012), comprova-se que a mudança fictiva de extensão espacial ocorre em dados de fala espontânea do PB. Ela se apresenta com estrutura muito semelhante a dos exemplos elaborados pelos autores de referência da LC. A conversa (6), na qual a mudança fictiva de extensão espacial se realiza, foi gravada em um espaço público, mais especificamente em uma loja de roupas na cidade de Belo Horizonte, capital do estado de Minas Gerais (Brasil). Os participantes são:

JAN, Janayna (mulher, estudante de nível médio, de São Paulo/SP, mas mora em Belo Horizonte/MG).

TAT, Tatiana (mulher, vendedora, participante de Belo Horizonte/MG).

CCB (desconhecido, cliente, interveniente)

Na interação, JAN está comprando roupas e é atendida pela vendedora TAT. O tópico, portanto, é "comprando roupas", e o diálogo se dá pela variação informal da língua portuguesa, como é característico do enquadre da situação cotidiana e da fala espontânea.

(6) *TAT: [199] e aí/gostou de alguma coisa //\$

*CCB: [200] quanto que tá essa daqui //\$

*TAT: [201] essa / trinta-e-nove e noventa //\$

*TAT: [202] xá eu até conferir / que é tanto preço //\$

*TAT: [203] trinta-e-nove e noventa //\$

${ }^{*}$ CCB: [204] essa aqui eu vou levar $/ / \$$

*TAT: [205] essa é/pê //\$

${ }^{*}$ CCB: [206] mas eu acho que esse Et [/3] que o decote aqui vai ficar coisa nela //\$

*TAT: [207] tendi / cê tá achando que vai ficar muito / <aberto > //\$

${ }^{*}$ CCB: $[208]<e ́>/ / \$$

${ }^{*} C C B:$ [209] essas aqui são quanto //\$ 
${ }^{*}$ TAT: [210] dezenove e noventa //\$

*JAN: [211] cê tem dessa aqui eme //\$

${ }^{*}$ TAT: [212] tenho //\$

*JAN: [213] que eu acho que aquela ficou muito camiseta //\$

${ }^{*}$ TAT: [214] tendi //\$

*TAT: [215] vou pegar pra você $/ / \$$

*JAN: [216] hum hum // \$

(bpubd1065 , C-ORAL BRASIL, RASO \& MELLO, 2012)

(6) *JAN: [213] que eu acho que aquela ficou muito camiseta //\$

Em (6), tem-se o predicado de mudança fictiva, por meio do qual a dimensão espacial é conceptualmente alterada. A cena se configura de modo que JAN experimenta diversas peças de roupas tamanho " $\mathrm{P}$ " (pequeno), e uma delas, apesar de ser também "P", é ainda menor do que o esperado. Então, a quebra da expectativa default gera um ambiente discursivo apropriado para a mudança fictiva. A peça de roupa em questão não tem suas dimensões nem seu modelo alterados factivamente, mas fictivamente, por conta da nova imagem construída dessa mesma peça de roupa durante a experiência de vesti-la. Pelo menos no Brasil, blusa e camiseta são peças de roupa cujo formato se distingue substancialmente, como se vê na figura 2:

Figura 2 - Blusa (esquerda) e camiseta (direita)
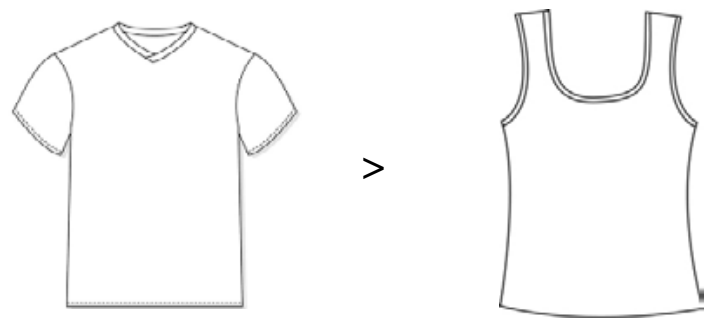

5 Esse código se refere aos arquivos de texto do corpus C-ORAL-BRASIL.

Desse modo, levando-se em consideração (6), ocorre uma mudança não genuína que se dá apenas de acordo com a percepção do conceptualizador, no caso JAN. A mudança fictiva é uma construção linguística pervasiva, tanto que o 
interlocutor TAT expressa sua compreensão acerca do que JAN disse nas linhas [214] e [215], ao expressar "tendi", que significa "entendi", e "vou pegar pra você", demonstrando que pretende atender à demanda da consumidora pelo tamanho "M" (médio). Portanto, o emprego da construção de mudança fictiva contribui para a interação entre as interlocutoras, pois essa percepção não factiva é partilhada.

\subsection{Extensão temporal}

As ocorrências de predicados de mudança fictiva de extensão temporal podem ser emblematicamente representadas pelo seguinte exemplo extraído de Talmy (2000. p. 170):

(7) The entering freshmen keep getting younger.

'Os calouros ficam cada vez mais jovens.'

A sentença (7) pertence a um professor, que, factivamente, está se tornando mais velho, enquanto os estudantes (calouros) ingressam jovens na vida acadêmica, com uma mesma faixa etária. No entanto, a sentença demonstra fictivamente uma idade estática para o professor, ao passo que os alunos mudam de idade, de modo decrescente. Os predicados de extensão temporal, de caráter fictivo, dão-se a partir de mudanças factivas, como o envelhecimento do professor e a renovação periódica das turmas de alunos, as quais instauram a expectativa default acerca das rotinas acadêmicas. O professor promove um escaneamento mental da cena factiva conforme suas próprias impressões subjetivas, que contrariam tal expectativa default e criam um domínio não-genuíno (virtual), partilhado intersubjetivamente.

A verificação empírica da ocorrência de mudança fictiva de extensão temporal em corpus de PB traz como um dos exemplos o excerto (8), cuja gravação foi realizada na cidade de Betim (MG), na residência dos participantes. Classifica-se o excerto como diálogo informal familiar, do qual participam:

CAR, Carlos (homem, professor e trabalha também como administrador regional de um partido político, filho/participante, de Inhapim-MG, mas mora em Betim-MG há 20 anos) 
ONO, Onofre (homem, comerciante, pai/participante, de Inhapim-MG, mas mora em Betim-MG há 20 anos)

TIT, Titina (mulher, dona de casa, mãe / participante, de Inhapim-MG, mas mora em Betim-MG há 20 anos)

O tópico é "almoço em família", e a cena apresenta a seguinte situação: conversa entre mãe, pai e filho, referente a eventos da semana decorrida, enquanto se servem do almoço.

(8) *TIT: [158] tempero ficou bom / dos frango //\$

*ONO: [159] bom //\$

*TIT: [160] tem verdura na geladeira //\$

${ }^{*}$ TIT: [161] cê nũ quis não / Onofre //\$

*CAR: [162] sio' vai querer / <mãe $>/ / \$$

*ONO: [163] <quê> //\$

*TIT: [164] eu quero um tiquinho //\$

*TIT: [165] um pouquinho só //\$

*ONO: [166] limão //\$

*TIT: [167] Everdu [/1] hhh legumes //\$

*ONO: [168] quero não //\$

${ }^{*}$ CAR: [169] aqui o' //\$

${ }^{*}$ ONO: [170] <tem $\mathcal{E} c 0>+\$$

*CAR: [171] <senhora vai comer> é de colher ou de garfo / mãe //\$

${ }^{*}$ TIT: [172] garfo //\$

*TIT: [173] houve um tempo que eu era criança e comia de colher //\$

${ }^{*}$ CAR: [174] ahn $/ / \$$

*TIT: [175] houve um tempo que eu fiquei criança outra vez //\$

${ }^{*}$ CAR: [176] quando sio' era criança //\$

*TIT: [177] não //\$

*TIT: [178] Efi [/1] houve um tempo atrás aí eu comia de colher //\$

*TIT: [179] agora eu cresci de novo //\$

*CAR: [180] cresceu de novo //\$

*TIT: [181] hum hum //\$

${ }^{*}$ CAR: [182] mais //\$

*TIT: [183] não/ tá bom //\$

*ONO: [184] o' / quando cê for pôr o frango <frito $>/ / \$$

(bfamcv11, C-ORAL BRASIL, RASO \& MELLO, 2012) 
(8) a. TIT: houve um tempo que eu fiquei criança outra vez b. TIT: agora eu cresci de novo

Os enunciados (8a) e (8b) expressam mudança fictiva de extensão temporal, inseridos em um fluxo discursivo ancorado, pelo menos, em três domínios temporais: (i) ao tempo em que TIT era criança e comia com colher; (ii) à fase adulta em que se comporta como criança ao comer com colher; e (iii) ao momento atual em que supostamente come com garfo, comportando-se como adulta.

O enunciado (8a) remete à transição fictiva entre os domínios temporais (i) e (ii), no qual um espaço mental de passado é construído por intermédio da expressão "houve um tempo", e onde se adicionam informações acerca da mudança fictiva, ou seja, tornar-se criança outra vez.

Em (8b), enunciado relativo à transição fictiva entre os domínios temporais (ii) e (iii), o conceptualizador introduz a expressão temporal "agora", fazendo-a coincidir com o centro dêitico do discurso, o aqui-e-agora da enunciação. Com isso, adiciona ao verbo "crescer", no passado, um aspecto pontual, que exprime ação momentânea. Isso faz com que o significado do verbo se torne fictivo, haja vista que o crescimento humano não opera de modo rápido. A expressão "de novo" encerra o enunciado, perfilando uma iteratividade fictiva na transição entre infância e vida adulta.

Por meio de (8a) e (8b), TIT explicita um mapeamento mental entre o ato de comer com colher e o período da infância; e entre o ato de comer com garfo e o período da vida adulta. Essa correspondência cognitiva é socioculturalmente licenciada, pois, por conta das diferentes habilidades no manejo de utensílios domésticos, crianças costumam usar colheres e adultos, garfos. Nesse caso, a categoria tempo é metonimicamente acessada por conta da função pragmática de que o uso de determinado objeto pode estar circunscrito a um determinado período de tempo da vida.

A mudança factiva (voltar a comer com colher/voltar a comer com garfo) lança as bases da ocorrência de mudança fictiva (ficar criança outra vez/crescer de novo), por meio do processo metonímico em que o conceptualizador toma o uso de um instrumento por um período de tempo. Nesse caso, a 
metonímia é o processo do qual se vale o conceptualizador para realizar o predicado de mudança fictiva. TIT, na condição de mulher, dona de casa e mãe, afirma que voltou a se comportar como uma criança na fase adulta, isto é, voltou a comer com colher, o que sinaliza uma mudança factiva. Todavia, os atos de "ficar criança outra vez" e "crescer de novo" só podem ser compreendidos no plano fictivo. Para evidenciar a impressão de viagem no tempo do conceptualizador, contrastam-se os enunciados factivo e fictivos de TIT:

Construção Factiva:

TIT: [173] houve um tempo que eu era criança e comia de colher

Construção Fictiva (excerto 8a e 8b):

TIT: [175] houve um tempo que eu fiquei criança outra vez

TIT: [179] agora eu cresci de novo

Assim, a mudança ocorre somente no plano virtual do conceptualizador TIT, já que o tempo cronológico não pode ser objetivamente alterado mediante o uso de colher ou garfo.

\subsection{Extensão corporal}

O estudo do corpus revelou uma nova categoria de predicados de mudança fictiva, não mencionada pelos trabalhos seminais acerca do tema. O que fomentou a postulação dessa categoria foi a descoberta, via rastreamento de verbos de mudança no corpus, de diferentes ocorrências de extensão fictiva, além da espacial e temporal. Também imersos em ambiente discursivo de descrição e narração, os predicados de mudança fictiva de extensão corporal se apresentam como uma impressão subjetiva do conceptualizador sobre dimensões corporais, as quais podem reduzir ou aumentar fictivamente em termos de tamanho, massa, peso e volume.

O caráter subjetivo desses predicados não impede que a impressão seja partilhada entre os demais conceptualizadores. Assim como ocorre com os predicados de extensão espacial e temporal, os predicados de extensão corporal apresentam possibilidade de partilhamento por conta de suas bases mentais e psicológicas calcadas em percepções visuais, convenções culturais, experiências físicas e sociais. A contrapartida do 
cenário efetivo também corrobora a existência da mudança fictiva de extensão corporal, à medida que uma mudança no plano factivo deve necessariamente ocorrer para que a transição fictiva se dê.

No diálogo (9), a seguir, realiza-se um típico predicado de mudança fictiva de extensão corporal. Gravada em uma loja de sapatos, na cidade de Belo Horizonte (MG), a conversa envolve o enquadre de comércio: na loja, o vendedor mostra à cliente uma série de diferentes modelos de sandálias com seus respectivos preços. A situação de fala configura um diálogo informal e público, cujo tópico é "escolhendo sandálias para comprar" e do qual participam:

EUG, Eugênio (homem, vendedor da loja de sapatos, participante, Belo Horizonte-MG)

JAN, Janayna (mulher, cliente participante, de São Paulo-SP, mas reside em Belo Horizonte- MG)

WOA (mulher, outra cliente, interferente no diálogo entre JAN e EUG)

(9)*EUG: [155] pôs na liquidação por cinquenta-e-nove / quando tava na liquidação $/ / \$$

*EUG: [156] aqui o' / essa aqui que eu achei dela pretinha //\$

*EUG: [157] achei Piccadilly/trinta-e-nove lá dentro //\$

*EUG: [158] sandália básica / da Piccadilly //\$

*EUG: [159] <e aquela> +\$

*JAN: [160] <nts $>/ / \$$

*JAN: [161] <essa> aqui não fecha no meu pé //\$

*JAN: [162] apesar que meu pé tá meio sujo / né //\$

*JAN: [163] então não fecha //\$

*EUG: [164] xá eu ver / a pulseirinha nũ deu não //\$

*JAN: [165] não //\$

*EUG: [166] não / fechar / fecha / mas / bem a conta / né //\$

*EUG: [167] olha aqui o' //\$

*EUG: [168] no segundo furinho o' //\$

*EUG: [169] <nũ sei se eu apertei demais> hhh //\$

*JAN: [170] <ô e ela é bonitinha> //\$

*JAN: [171] é/ ela é muito $\mathcal{E} b o+\$$ 
*JAN: [172] é que o meu pé é grande mesmo //\$

*JAN: [173] mas ea é muito <bonitinha $>/ / \$$

*EUG: [174] <esse que cê tá> experimentando grafite / tem preto / e / grafite assim //\$

*WOA: [175] oh/meu pé fica miudinho hhh //\$

*EUG: [176] ele é uma sapatilha / de saltinho $<$ Anabella $>/ / \$$

*WOA: [177] <de>+\$

*WOA: [178] é//\$

${ }^{*}$ EUG: [179] couro //\$

*WOA: [180] é $/ / \$$

*WOA: [181] aqui //\$

*EUG: [182] <essa é seu> número //\$

(Bpubd102, C-ORAL BRASIL, RASO \& MELLO, 2012)

(9) WOA: oh, meu pé fica miudinho.

No enunciado (9), o falante WOA afirma que uma parte de seu corpo teve as dimensões reduzidas pelo fato de experimentar um determinado modelo de calçado. A impressão de mudança fictiva de extensão corporal é perfilada por um enunciado com verbo no tempo presente ("fica", similar a "torna-se"), simultâneo ao centro dêitico do discurso e evocador do frame de transformação, que se encerra em um estado final ("miudinho" ou muito pequeno).

O conceptualizador de (9) descreve sua impressão visual acerca do próprio corpo, lançando mão de um predicado de mudança que sugere redução, fictiva e não factiva, do tamanho do pé. Como é contrário à expectativa default de que um calçado possa reduzir as dimensões do pé, o enunciado (9) não poderia ser interpretado como mudança factiva, haja vista que a transformação dá-se apenas no plano virtual. Logo, o predicado é de mudança fictiva, de característica corporal, já que essa percepção, fomentada pelo sentido da visão, é ilusória.

A natureza fictiva de (9) aponta também para incursões metonímicas. Ao se referir ao próprio pé, no enunciado, WOA não perfila a informação de que o pé está calçado, apenas toma pé por pé calçado. Isso sinaliza a conceptualização de limites virtuais que envolvem os predicados de mudança fictiva de extensão corporal. O pé calçado é enquadrado apenas como pé, pois o que calça o pé é concebido como sua própria extensão. 
Trata-se, então, de uma mudança fictiva, em que há imposição de uma extensão que mentalmente diminui as dimensões reais do referente. Esse limite é virtualmente reduzido, mesmo que as dimensões físicas permaneçam as mesmas.

No excerto (10), a seguir, há ocorrência de outro caso de mudança fictiva de extensão corporal. O diálogo se passa em um hospital da cidade de Belo Horizonte (MG). Os participantes da conversa são:

ATA, Atanagildo (homem, male, médico cirurgião e amigo, de Araxá-MG)

JON, Jonathan (homem, operador de equipamentos industriais pesados, paciente, de Belo Horizonte-MG)

MNV, Manoel (homem agricultor, paciente, de Pedralva-MG) SID, Sidnei (homem, empregado de transportadora, paciente) PRI, Priscila (mulher, estudante, filha de ATA, de Belo Horizonte-MG)

Trata-se de uma conversa informal, do tipo familiar privada, entre pacientes e um amigo que foi visitar um desses pacientes. O principal assunto são os motivos que os levaram ao hospital e um relato sobre a experiência de um terceiro amigo.

(10) *ATA: [33] e ocê / como é que arrumou isso aí //\$

*ATA: [34] a junta foi / endurecendo e ocê pôs outra [/1] um +\$

${ }^{*} M N V:$ [35] é//\$

${ }^{*} M N V:[36]$ foi //\$

*MNV: [37] a perna começou a doer / né //\$

*MNV: [38] começou a doer / eu falei / uai //\$

*MNV: [39] que negócio é esse //\$

${ }^{*} M N V:[40]$ aí/eu +\$

*ATA: [41] mas antes de operar a primeira vez / né//\$

${ }^{*} M N V:[42]$ antes de operar $/ / \$$

*MNV: [43] primeira vez //\$

${ }^{*} M N V:[44]<a i ́>+\$$

*ATA: [45] <foi> +\$

*ATA: [46] aí dava o frio e a junta nũ dobrava //\$

*MNV: [47] não/ ué/a perna começou a \&fu [/1] ficar mais comprida / né //\$

*ATA: [48] uai $/<$ credo $>/ / \$$ 
*MNV: [49] <aí eu> / falei / uai //\$

*MNV: [50] isso aí vai ficar parecendo bico de arado que tá pegando avião //\$

*ATA: [51] hhh <bico de $>$ arado //\$

*MNV: [52] <aí> +\$

*MNV: [53] é/né//\$

*MNV: [54] <aí / eu> / fui lá <ni> Tajubá co doutor Luciano / mas ele tirou a chapa / que tem que operar / seu Mané //\$

*JON: [55] <ahn> //\$

*JON: [56] <mas $>+\$$

*MNV: [57] <falei> / ih/e é urgente / ainda / né //\$

(Bfamcv13, C-ORAL BRASIL, RASO \& MELLO, 2012)

(10) a. MNV: [37] a perna começou a doer, né

b. MNV: [47] não ué, a perna começou a ficar mais comprida, né

Em (10a), MNV descreve o sintoma factivo que o levou a realizar uma cirurgia. Nesse momento, há ocorrência de um predicado de mudança factiva: sua perna passa do estado de aparentemente saudável ou sem dor para o estado dolorido. Essa configuração de cena, contendo mudança factiva, instaura as bases discursivas para a realização da mudança fictiva em (10b). Portanto, a mudança factiva não precede coincidentemente a mudança fictiva, pois a primeira pré-enquadra a possibilidade de ocorrência da segunda.

Em (10b), a estrutura da mudança fictiva se assemelha à da mudança factiva, porém o complemento da expressão "começou a" é o verbo de mudança "ficar" (tornarse). Diferentemente de "doer", o verbo "ficar" não tem sentido lexicalizado pleno e necessita de complemento. $\mathrm{O}$ conceptualizador completa o sentido do verbo "ficar" com a expressão "mais comprida". No entanto, a expectativa default é a de que pernas cresçam vagarosamente ao longo da infância e adolescência. Sendo MNV um homem adulto, sua perna não poderia começar a crescer factiva e instantaneamente, tal como pode começar a doer. Logo a estrutura engendra uma quebra da expectativa default, configurando a mudança 
fictiva, que é corroborada pelo conceptualizador ATA, ao se espantar com isso na linha 48: "uai / <credo>".

O recorte dos dados esclarece a distinção entre a mudança factiva e a fictiva; a primeira é concebida como plausível e real, pois a dor compõe o novo estado físico do corpo; enquanto a segunda é concebida como implausível e irreal, porque revela uma sensação psicológica do conceptualizador $\mathrm{MNV}$ em relação ao seu corpo, que não tem seu comprimento redimensionado devido à dor. Dessa forma, esse enunciado também caracteriza uma mudança fictiva de extensão corporal, ocorrida em ambiente discursivo de descrição.

Outra instância empírica de predicado de mudança fictiva de extensão corporal ocorre em (11). O diálogo se passa em uma academia de ginástica em Belo Horizonte (MG), do qual participam:

TOM, Tommaso (homem, professor universitário, de Nápoles-Itália, filho de mãe brasileira e pai italiano, mora em Belo Horizonte-MG desde 2004)

GUI, Guilherme (homem, personal trainer, de Montes Claros-MG) PAA, desconhecida (mulher, interveniente)

A situação envolve o diálogo entre o personal trainer GUI e seu cliente TOM, durante uma sessão fitness. Nessa circunstância, GUI dá instruções de como TOM deve fazer os exercícios. TOM descreve como se sente a cada exercício, respondendo às instruções:

(11) *GUI: [425] olha pra frente / relaxa aqui / peito pra frente / encaixa aqui atrás /

*GUI: [426] o ombro //\$

*GUI: [427] aí //\$

*GUI: [428] peito pra frente //\$

*GUI: [429] beleza //\$

*GUI: [430] agora / eleva mais os cotovelos / boa //\$

*GUI: [431] agora tá numa posição melhor $/ / \$$

*GUI: [432] no caso do squash / esse aí / que é o que mais prejudica / né //\$

*TOM: [433] <Enã > + \$

*GUI: [434] <ombro> //\$

*TOM: [435] é/eu [/1] mas eu acho +\$ 
*TOM: [436] é ombro / e / <o> / bícep e o trícep / né //\$

*GUI: [437] ah/tá//\$

*GUI: [438] assim / o [/1] o braço fica pesado //\$

*TOM: [439] é/fica //\$

*TOM: [440] <fica travado> //\$

*GUI: [441] <pesado> //\$

*GUI: [442] ham ham //\$

*GUI: [443] vão lá //\$

*TOM: [444] mas só no começo / só até esquentar //\$

*GUI: [445] ham ham //\$

(Bpubd103, C-ORAL BRASIL, RASO \& MELLO, 2012)

(11) GUI: [438] assim o braço fica pesado

O excerto (11) também é típico de mudança fictiva de extensão corporal e confirma a hipótese de que ambientes discursivos de descrição são propícios para a ocorrência da mudança fictiva. GUI descreve, para seu cliente, uma sensação corporal de fadiga muscular, decorrente da realização dos exercícios. Assim se configura o cenário de mudança factiva, ou seja, o braço passa do estado de descansado a cansado. Tal mudança real constitui as bases discursivas que produzem a sensação expressa pelo predicado de mudança fictiva de extensão corporal. Essa, por sua vez, consiste no fato de que o braço não pode ter seu peso instantaneamente aumentado por conta da fadiga. As linhas 439 a 442 endossam o compartilhamento, entre os participantes, da operacionalidade interacional da construção de mudança fictiva de extensão corporal.

\section{Bloqueio da mudança fictiva}

Com base em Langacker (2008) e Talmy (2000), o conceito geral de fictividade abarca um conjunto complexo de processos e produtos da cognição humana, voltado para a estruturação da linguagem e do pensamento. Nesse sentido, movimentos e mudanças são reificados por perspectivação conceptual, através de vetores virtuais alternativos, ora mais ora menos fictivos. Suas bases remetem à verossimilhança atribuída a aspectos como visão, linguagem, memória, imaginação e conhecimento. Isso significa dizer que a conceptualização/ 
perceptualização da realidade física é sustentada pela mimesis criativa promovida pela cognição. O slogan "parece-masnão-é" abrange casos de fictividade representada já discutidas na literatura de LC, como as expressões de movimento (e.g. A tatuagem vai de um ombro ao outro), mudança (e.g A sala ficou maior depois que tiramos os móveis) e interações (ironias e perguntas retóricas) fictivas.

No exame das ocorrências em dados de fala espontânea, observaram-se restrições no uso de predicados de mudança fictiva - e talvez elas sejam aplicáveis a outras manifestações de fictividade na linguagem. Tais restrições são determinadas pela explicitação da natureza verossímil da impressão por meio do uso de marcas linguísticas reveladoras do fenômeno, que se estabelece no slogan "parece-mas-não-é". O verbo "parecer" se mostrou relevante para a função bloqueadora do fenômeno.

A análise do excerto (12) apresenta um exemplo de bloqueio da mudança fictiva. O diálogo ocorre na casa de uma família, na cidade de Belo Horizonte (MG), em que três irmãs conversam, durante o café da tarde, sobre o casamento da filha de uma delas. Logo, as participantes são:

RUT, Rute (mulher, professora aposentada, participante, de Belo Horizonte-MG)

TER, Terezinha (mulher, dona de casa, participante, de Belo Horizonte- MG)

JAE, Jael (mulher, professora aposentada, participante, de Belo Horizonte-MG)

6 Outras expressões podem servir como bloqueadoras do fenômeno da mudança fictiva, tais como: "que nem", "igual", "feito" e "tipo", as quais podem evidenciar comparação entre elementos, marcando uma impressão explícita.
Nessa cena, estabelece-se uma conversa informal, do tipo familiar privada. $\mathrm{O}$ assunto abrange decisões que vão desde os convidados até os comentários acerca das roupas e dos penteados a serem usados por cada uma delas no evento.

(12) *JAE: [267] inda bem que cê vai tar co seu cabelo curto / pa nũ fazer aquela touca pra cima $/ / \$$

*JAE: [268] porque Deus me livre //\$

*RUT: [269] uai / ocê nũ gostou <não / Jael> //\$

*JAE: [270] <não / eu nũ > gosto de jeito nenhum //\$

${ }^{*}$ TER: [271] $<$ oh $>/ / \$$

*RUT: [272] o' / a Jael nũ gosta de [/1] de cabelo preso não //\$

*RUT: [273] o' $p^{\prime} c \hat{e}<v e r>/ / \$$ 
*TER: [274] <é> //\$

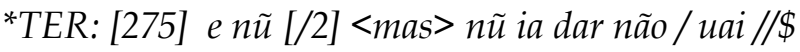

*RUT: [276] $<x x x>/ / \$$

*TER: [277] $\mathcal{E d}[/ 1] \mathrm{ia} /<$ Rute $/ / \$$

*JAE: [278] <parecendo aquelas velhinha> //\$

*TER: [279] se eu fizesse> //\$

*TER: [280] se eu <fizesse> $/ / \$$

*JAE: [281] <ficou parecendo aquelas > velhinha / do [/1] da carinha pequenininha //\$

*JAE: [282] não //\$

*JAE: [283] nũ <gostei> //\$

(Bfamcv02, C-ORAL BRASIL, RASO \& MELLO, 2012)

(12) a. JAE: [270] não, eu nũ gosto de jeito nenhum

b. JAE: [278] parecendo aquelas velhinha

c. JAE: [281] ficou parecendo aquelas velhinha da carinha pequenininha

Nota-se que, em (12c), a semântica do verbo "parecer" denuncia que se trata tão somente de uma impressão do conceptualizador e de que ele está ciente do caráter apenas sensório de sua percepção. Na ausência do verbo "parecer", o caráter fictivo se manifestaria no enunciado. Já com a presença do "parecer", denotando aparência de estado, não há fictividade manifesta. É possível, então, postular um teste de bloqueio de fictividade nas ocorrências de mudança fictiva apresentadas ao longo deste artigo, com a substituição do verbo de mudança pelo verbo "parecer" ou com uso do prefácio "parece que", introduzindo o enunciado fictivo:

-Parece que a casa fica muito espaçosa depois da instalação de espelhos.

- A casa parece muito espaçosa depois da instalação de espelhos

-Parece que o quarto ficou redondo.

- O quarto parece redondo.

- Parece que a cerca fica maior à medida que você desce a rua.

- A cerca parece maior à medida que você desce a rua.

-Parece que aquela ficou muito camiseta

- Aquela parece muito camiseta 
-Parece que os calouros ficam cada vez mais jovens.

- Os calouros parecem cada vez mais jovens.

-Parece que houve um tempo que eu fiquei criança outra vez.

- Houve um tempo que eu parecia criança outra vez.

- Parece que agora eu cresci de novo.

- Agora eu pareci crescer de novo.

-Parece que a perna começou a ficar mais comprida, né.

- A perna começou a parecer mais comprida.

-Parece que assim o braço fica pesado.

- Assim o braço parece pesado.

O emprego de "parecer" nos exemplos anteriores evoca um domínio de verossimilhança explícita entre o que se concebe/percebe subjetivamente e o que se concebe/percebe objetivamente. Isso bloqueia a fictividade da mudança, porque a comparação entre o "ser" e o "parecer" não é fundo, mas figura. Quando ocorre verossimilhança implícita, com a ausência do "parecer", a mera comparação entre eles é subfocalizada, e o que está sendo perfilado é a mudança fictiva. Nesse caso, pode ser que ainda se instaure um conflito cognitivo entre "ser" e "parecer". Isso não necessariamente acarreta uma dissensão do ponto de vista interacional, em termos de verificação das condições de verdade das aparências. Em outras palavras, os conceptualizadores usualmente não se questionam quanto à validação da expressão de mudança fictiva, pois esse conflito cognitivo é partilhado entre os sujeitos. Por fim, o bloqueio da fictividade, em geral, dar-se-ia por meio de expressões que sugerem a explicação ou explicitação de impressões incongruentes com a realidade.

\section{Conclusão}

Conclui-se que a mudança fictiva, abordada teoricamente pelos autores de referência em LC, é de fato um fenômeno linguístico existente também no Português do Brasil. Por meio de investigação empírica em dados de fala espontânea, delimitaram-se padrões de predicados, os quais podem ser arregimentados em três tipos: extensão espacial, extensão temporal e extensão corporal. Em geral, verificou-se que a ocorrência do fenômeno se dá na configuração de uma cena 
que envolve, primeiramente, uma mudança efetiva, no plano real. Essa mudança factiva é que possibilita a ocorrência da mudança fictiva, linguisticamente marcada pelo "filtro" da cognição intersubjetiva.

Não se deve entender, então, a mudança fictiva como algo subjetivo ou particular, pois esse plano conceptual e perceptual é compartilhado, sem prejuízo interacional. Trata-se enfim de um fenômeno constituído intersubjetivamente e de uma evidência semântico-cognitiva de que a linguagem constitui o mundo e que os predicados de mudança objetiva servem como base para o escaneamento mental do conceptualizador sobre dimensões espácio-temporais e corporais. As construções de mudança fictiva semanticamente apresentam uma noção de transformação estimulada pela presença de um verbo de mudança, que é construcionalmente fictivizado.

No entanto, se o conceptualizador emprega o verbo "parecer", ocorre o bloqueio da mudança fictiva. Dessa forma, fica linguisticamente explícita sua conscientização acerca de sua percepção sensorial e imaginativa. Por outro lado, a construção característica da mudança fictiva, sem o emprego desse verbo, transcende a realidade, produzindo enunciados com quebra da expectativa default e, por isso, semanticamente estranhos ou inusitados, fazendo com que a mudança exista apenas no plano conceptual e perceptual. A natureza da mudança fictiva se alinha ao fato de que, na experiência, não podemos, boa parte das vezes, fazer distinção entre ilusão e percepção, conforme aponta Maturana (2001). Mesmo sob o efeito da explicação, continuamos cotidianamente a conceber ou a perceber mudanças que não acontecem de fato.

\section{REFERÊNCIAS}

LANGACKER, Ronald W. Foundations of Cognitive Grammar, vol. 1: Theoretical Prerequisites. Stanford: Stanford University Press, 1987.

LANGACKER, Ronald W. A view of linguistic semantics. In Topics in Cognitive Linguistics, Edited by Brygida Rudzka-Ostyn. Current Issues in Linguistic Theory, 50, p. 49-90, 1988.

LANGACKER, Ronald W. Cognitive Grammar: a basic introduction. New York: Oxford University Press, 2008. 
MATSUMOTO, Yo. Subjective-change expressions in japanese and their cognitive and linguistic bases. In: FAUCONNIER, G.; SWEETSER, E. Spaces, worlds, and grammar. Chicago: The University Chicago Press, p. 124-156. 1996.

MATURANA, Humberto. Cognição, ciência e vida cotidiana. Belo Horizonte: UFMG, 2001.

RASO, Tommaso; MELLO, Heliana. C-ORAL-BRASIL 1: corpus de referência do português brasileiro falado informal. Belo Horizonte (MG): Editora UFMG, 2012.

ROCHA, L. F. M.. A autocitação fictiva: abordagem sociocognitiva de um tipo de fictividade discursiva em Português Europeu e Brasileiro. 2011. (Relatório de pesquisa).

ROCHA, L. F. M.; BARBOSA, G. R. P. ; SOUZA, E. D. ;SOUZA, E. H. V. O uso de entidades fictivas em corpus de fala do PB: evidências empíricas para a Linguística Cognitiva. Revista Portuguesa de Humanidades, v. 17, p. 61-80, 2013.

SILVA, Augusto Soares da. Significado, conceptualização e experiência: sobre a natureza do significado linguístico. Revista Portuguesa de Humanidades: Braga, v. 10 1/2: 13-40, 2006.

SWEETSER, Eve. Changes in figures and changes in grounds: A note on change predicates, mental spaces, and scalar norms. Cognitive Studies: Bulletin of the Japanese Cognitive Science Society, 3:3 (Sept. 1996 - Special Issue on Cognitive Linguistics), p. 75-86, 1996.

SWEETSER, Eve. Role and individual readings of change predicates. In: Language and Conceptualization, eds. J. Nuyts and E. Pederson. Oxford University Press, 1997.

TALMY, Leonard. How language structures space. In Herbert L. Pick, Jr. \& Linda P. Acredolo (eds.) Spatial orientation: Theory, research, and application. New York: Plenum Press, 1983.

TALMY, Leonard. Toward a cognitive semantics. 2 volumes. Cambridge, MA: Massachusetts Institute of Technology, 2000. 


\section{Abstract \\ Fictive change in Brazilian corpus of spontaneous speech}

This work investigates fictive change occurrences in spontaneous speech corpus of Brazilian Portuguese (BP) as The room got bigger after removing the furniture (O quarto ficou muito maior depois que retiraram os móveis), in which a change expressed by the predicate occurs only due to the perception of a conceptualizer. In other words, the room has not expanded its particular dimensions, but the resultative nature of this change occurs only in the subjective plan. Some authors in Cognitive Linguistics (CL) have been addressed this phenomenon (see SWEETSER, 1996, 1997, and MATSUMOTO, 1996), which shows that the vision of an object takes on another dimension, shape, or state when there is a change in the perception of the conceptualizer. Such theoretical aspects lay the foundations of empirical feasibility of fictive change in spontaneous speech data of PB. In this view, the methodology complies with the search for occurrences of change verbs (e.g. "become") in the informal part of the corpus C-ORAL-BRAZIL (RASO \& MELLO, 2012), associated with the listening of audio files and concomitantly to the study of the transcripts. Thus, temporal, spatial and bodily extent patterns were listed, in which the change is only subjective or fictive in nature. The results also point to the fact that the construction is related to a breakdown of default expectation, resulting in something that only occurs under a conceptual perspective.

Keywords: Cognition; Fictivity; Fictive Change; Corpus; Spontaneous Speech. 